\title{
Pela construção de um novo pacto social equitativo, ético e solidário
}

\author{
[...] a busca concentrada no crescimento econômico, elaborada por comportamentos motivados pela ganância, resultou em conse- \\ quências negativas, muito além dos setores financeiros e econômicos. [...] Não sou contra o livre comércio. Não sou a favor do prote- \\ cionismo. Sou totalmente consciente dos estritos vínculos entre maior prosperidade econômica, em níveis nacionais e domésticos e \\ melhor saúde. Mas não preciso dizer isso. O mercado não soluciona os problemas sociais. É a saúde pública quem o faz. (Margareth \\ Chan, Diretora Geral da Organização Mundial da Saúde, Istambul, abril de 2009).
}

A realização da nona edição do Congresso Brasileiro de Saúde Coletiva, entre 31 de outubro e 04 de novembro de 2009, em Recife coincide com um período extremamente conturbado. A atual crise do sistema financeiro internacional vem produzindo um impacto direto sobre a saúde e qualidade de vida dos povos, sem precedente em nossa história recente. A Carta de Olinda - produto deste Congresso - expressa de forma contundente nossa atual conjuntura, propondo a reversão do atual sistema de produção, acumulação e distribuição de riquezas por "um novo modelo que promova a saúde e a qualidade de vida, em um padrão sustentável de desenvolvimento que permita a superação das iniquidades sociais."

Mais uma vez, os números desse Abrascão surpreendem e renovam a energia da comunidade de Saúde Coletiva brasileira e a capacidade de convocação da Associação Brasileira de Pós-Graduação em Saúde Coletiva (ABRASCO). Foram 10.731 resumos inscritos! Deste total a Comissão Científica selecionou 8139 trabalhos e experiências para serem apresentados (600 em formato oral e 4392 na modalidade de pôster) e publicados (3147) nos anais do Congresso - suplemento da Revista Ciência e Saúde Coletiva. Mais de seis mil participantes estiveram presentes!!

O tema central - "Compromisso da Ciência, Tecnologia e Inovação com o Direito a Saúde", os trabalhos selecionados e as contribuições de múltiplos atores e instituições parceiras serviram de substrato para a Comissão Científica na definição de uma programação que contemplou 4 conferências, 12 grandes debates, 4 palestras, 61 painéis, 9 discussões temáticas, 106 comunicações coordenadas. As quatro dimensões sugeridas a partir do temário central - Ciência, Tecnologia e Inovação para o cumprimento dos princípios e diretrizes do Sistema Único de Saúde (SUS); Saúde e Seguridade Social; Desenvolvimento Social e Econômico Sustentável; e Garantia dos Direitos Humanos - contribuíram na organização e no estimulo ao debate e buscaram garantir por um lado a visibilidade às abordagens e práticas inovadoras em resposta aos atuais desafios, e por outro, a uma revisita aos conceitos e princípios celebrados recentemente com os 60 anos da Declaração Universal dos Direitos Humanos; os 30 anos da Declaração de Alma Ata e os 20 anos da Constituição Brasileira.

A presença de profissionais de saúde; professores e pesquisadores do campo; de gestores de todos os níveis do SUS, incluindo o Ministro de Estado de Saúde, José Gomes Temporão; lideranças civis e a participação ativa do Presidente da República, Luiz Inácio Lula da Silva, garantiram ao Abrascão 2009 as interlocuções necessárias entre as políticas de Estado, a academia, os serviços e movimentos sociais. O foco na Saúde Coletiva/Pública e no atual contexto nacional e internacional de crises e desafios transformaram os auditórios do Centro de Convenções de Pernambuco no maior cenário de debates de idéias e proposições em defesa da saúde e qualidade de vida dos brasileiros.

Todos aqui sabem que a ABRASCO veio fortalecendo o seu papel ao longo da década de 90, quando a maior preocupação na área da saúde era garantir as conquistas obtidas com a nova Constituição e assegurar a implementação do modelo de gestão em saúde definido pelo SUS. (Luiz Inácio Lula da Silva, Presidente da República, durante o IX Congresso Brasileiro de Saúde Coletiva. Olinda, Pernambuco, 03 de novembro de 2009).

Com base nos valores históricos defendidos pela comunidade de saúde coletiva brasileira - universalidade, equidade, participação social, democracia, cidadania - as sessões programadas fomentaram a discussão, reflexão e análise propositiva de múltiplos temas, focando a questão da propriedade intelectual, as inovações e o direito a saúde; os impactos da judicialização da saúde e a gestão do SUS; a ética e a proteção dos sujeitos de 
pesquisa; os desafios da saúde mental e estratégias de superação; as agências e as políticas públicas de fomento as pesquisas e ao ensino; a graduação e a pós-graduação em saúde coletiva/pública. O trânsito necessário entre questões conjunturais e análises estruturais relacionadas ao campo da saúde coletiva fortaleceram e estimularam a manutenção e aprofundamento do debate sobre as relações público/privadas no setor; o sub-financiamento do SUS; a precarização do trabalho; os modelos de atenção em saúde; os cuidados primários e a promoção da saúde; os limites e oportunidades do programa Saúde da Família; o programa de aceleração do crescimento e a natureza central da qualidade de vida e saúde para o desenvolvimento; as respostas em relação as doenças negligenciadas e a recente epidemia de gripe; as ameaças do aquecimento global; a agroecologia e a segurança alimentar. Estas e outras questões foram abordadas a partir das visões e vivências múltiplas; de interesses e modelos de atuação heterogêneos.

A presença e o discurso contundente do Presidente da República nesta nona edição do "Abrascão", evocando ao Estado a missão de garantir o direto a saúde e a qualidade de vida para todos os brasileiros - sublinhou e re-novou o compromisso do Estado Brasileiro com o que está plasmado em nossa constituição.

[...] é preciso saber quantos governadores do Brasil estão colocando na saúde aquilo que a Constituição garantiu - $12 \%$, ou quanto ca-

da cidade tem garantido... Se o cidadão começar a colocar quadra de esporte como dinheiro na saúde, aí vai ficar difícil. Por isso nós

estamos querendo regulamentar a Emenda 29 e não é muito fácil. (Luiz Inácio Lula da Silva, Presidente da República, durante o IX

Congresso Brasileiro de Saúde Coletiva. Olinda-PE, 03 de novembro de 2009).

Se as crises e novos desafios são evidentes, são igualmente claras as oportunidades e necessidades de avanço àqueles comprometidos com a qualidade de vida e saúde para todos. Estamos seguros de que o IX Congresso Brasileiro de Saúde Coletiva - compromisso da ciência, tecnologia e inovação com direito a saúde - foi e será um espaço para a construção de um novo pacto social por uma sociedade mais equitativa, ética e solidária.

Álvaro Hideyoshi Matida 1

${ }^{1}$ Secretário Executivo da Associação Brasileira de Pós-Graduação em Saúde Coletiva (ABRASCO).

\section{Bibliografia}

Chan M. Opening Address of the XII World Public Health Conference; 2009 may 27 in Istanbul, Turkey. Available from: http://www.who.int/dg/speeches/2009/steadfast_midst_perils_20090428/en/ Accessed on 19 May 2009..

Silva LIL. Discurso proferido aos participantes do IX Congresso Brasileiro de Saúde Coletiva; 3 nov. 2009; Olinda, Pernambuco. 